\title{
HUBUNGAN PELAYANAN KONSELING KB TENTANG AKDR DENGAN CAKUPAN AKSEPTOR AKDR
}

\author{
Yefi Marliandiani, Krisnamurti \\ Prodi D-III Kebidanan Universitas PGRI Adi Buana Surabaya
}

\begin{abstract}
ABSTRAK
Program Keluarga Berencana yang sudah dijalankan sejak tahun 1970-an mampu menekan laju pertumbuhan penduduk. Menurut BKKBN dalam data statistik Indonesia periode tahun 2007 tentang pemakaian kontrasepsi di Indonesia yaitu 33,10\% menggunakan kontrasepsi suntik, 13,50\% menggunakan kontrasepsi pil, 5,20\% menggunakan IUD, 2,70\% menggunakan kontrasepsi implant dan 2,60\% menggunakan kontrasepsi mantap sedangkan sisanya sebesar 42,9\% menggunakan metode kontrasepsi lainnya. Dari akseptor KB tersebut yang paling rendah adalah penggunaan Kontrasepsi AKDR, ini dikarenakan tidak dilakukannya konseling tentang metode kontrasepsi dan pelayanan kontrasepsi yang diberikan oleh petugas kesehatan hanya berdasarkan permintaan calon akseptor.

Jenis penelitian ini Observasional analitik dengan pendekatan Cross Sectional dengan populasi 50 akseptor KB pada bulan september 2011 di RSIA Prima Husada. Pengambilan sampel dengan total sampling sejumlah 50 orang. Instrumen penelitian menggunakan kuesioner.

Analisa data digunakan adalah uji chisquare yaitu didapatkan hasil signifikan, menunjukkan bahwa tidak ada hubungan antara pelayanan konseling dengan cakupan $\operatorname{AKDR}(p=0,179)$.

Berdasarkan hasil penelitian diperoleh bahwa sebagian besar bidan dalam melakukan pelayanan KB melakukan konseling secara menyeluruh (80\%), cakupan AKDR di RSIA Prima Husada sebesar 20\%, dan tidak ada hubungan antara pelayanan konseling dengan cakupan AKDR
\end{abstract}

Kata kunci : Pelayanan Konseling, Cakupan AKDR

PENDAHULUAN

Program Keluarga Berencana yang sudah

dijalankan sejak tahun 1970-an mampu

menekan laju pertumbuhan penduduk.

Berdasarkan hasil survei BKKBN peserta

KB pada tahun 2006 mencapai 5,7 juta

orang dan pada tahun 2007 jumlah

akseptor KB pada WUS meningkat

menjadi 6,2 juta orang. Program KB

bertujuan untuk menjarangkan kelahiran.
Menurut BKKBN dalam data statistik

Indonesia periode tahun 2007 tentang

pemakaian kontrasepsi di Indonesia yaitu

$33,10 \%$ menggunakan kontrasepsi suntik,

$13,50 \%$ menggunakan kontrasepsi pil,

$5,20 \%$ menggunakan IUD, $2,70 \%$

menggunakan kontrasepsi implant dan

2,60\% menggunakan kontrasepsi mantap

sedangkan sisanya sebesar $42,9 \%$

menggunakan metode kontrasepsi lainnya. 
Hingga Desember 2010, total peserta KB aktif di Jawa Timur sebanyak 6.150 .153 orang atau $126,46 \%$ dengan prevalensi $76,95 \%$ terhadap jumlah pasangan usia subur (PUS) 7.992.674 peserta.Dari 6.150.153 peserta $\mathrm{KB}$ aktif, pengguna $\mathrm{KB}$ suntik sebanyak $48,2 \%$, pil $21,01 \%$, IUD atau spiral $14 \%$, implan 8,5\%, MOW 5\%, MOP 0,4\%. Sementara pengguna kondom $1,5 \%$.

Sedangkan diSidoarjo target KB aktif 49.910 peserta, KB pil $12.390(23,02 \%)$ akseptor, KB suntik $31.506 \quad(58,53 \%)$ akseptor, KB IUD 4366 (8,11\%) akseptor, KB implan 3094 (5,74\%) akseptor, KB kondom 1471 (2,73\%) akseptor, KB MOW 946 (1,74\%) akseptor, KB MOP 48 (0.09\%) akseptor (BKKBN 2010). Angka kegagalan Alat Kontrasepsi Dalam Rahim (AKDR) rendah hanya $0,01-0,02 \%$. Namun demikian AKDR kurang diminati oleh pasangan usia subur dikarenakan takut cara pemasangannya.
Berdasarkan data di RSIA Prima Husada Waru Sidoarjo pada tahun 2010, data peserta KB adalah sebagai berikut : Akseptor KB suntik $3261 \quad(92,9 \%)$ akseptor, KB pil 234 (6,6\%) akseptor, KB implant $23(0,48 \%)$ akseptor, akseptor IUD $10(0.08 \%)$. Melihat data diatas dapat diketahui kontrasepsi yang paling rendah digunakan adalah AKDR. Dari hasil studi pendahuluan yang dilakukan pada tanggal 18 Juni 2011 di RSIA Prima Husada Waru -Sidoarjo tentang pelayanan konseling KB terhadap 10 akseptor KB sebagian besar (70\%) tidak dilakukan konseling tentang metode kontrasepsi, pelayanan kontrasepsi yang diberikan oleh petugas kesehatan (bidan) hanya berdasarkan permintaan calon akseptor.

\section{METODE}

Jenis penelitian ini adalah observasional Analitik dengan desain "cross sectional" Penelitian di lakukan di RSIA Prima Husada Waru - Sidoarjo pada bulan juni s/d september 2011. 
Populasi dalam penelitian adalah 50 akseptor KB (10 pil,10 suntik, 10 implant, 10 IUD, 10 MOW) bulan september 2011

di RSIA Prima Husada Waru-Sidoarjo. Analisis data dilakukan dengan menggunakan software statistical progam sosial science (SPSS), berupa analisis bivariate, yaitu dilakukan terhadap dua variabel yang diduga berhubungan atau berkolaborasi. Dalam penelitian ini untuk analisa datadigunakan uji CHI SQUARE.

\section{HASIL PENELITIAN}

Tabel Distribusi frekuensi pelayanan konseling yang dilakukan tenaga kesehatan di RSIA Prima Husada Waru - Sidoarjo bulan September 2011

\begin{tabular}{l|l|l}
\hline $\begin{array}{l}\text { Pelayanan } \\
\text { Konseling }\end{array}$ & Jumlah & Prosentase(\%) \\
\hline Baik & 40 & 80 \\
\hline Kurang Baik & 10 & 20 \\
\hline \multicolumn{1}{c|}{ Jumlah } & 50 & 100 \\
\hline Sumber : Data Primer, 2011 &
\end{tabular}

Dari tabel diatas menunjukkan bahwa bidan di RSIA Prima Husada WaruSidoarjo sebagian besar melakukan konseling dengan baik sebanyak 40 orang dengan prosentase $80 \%$ sedangkan sebagian kecil tidak melakukan konseling sebanyak 10 orang dengan prosentase $20 \%$.

Dari hasil wawancara 50 akseptor para akseptor mengungkapkan bahwa bidan melakukan tahapan konseling sesuai dengan teori, materi dan media yang diberikan ataupun yang digunakan sangat membantu klien untuk memastikan KB yang akan digunakan ataupun yang akan dipilih, jadi tidak ada keraguan dengan kontrasepsi yang akan dipilih ataupun yang akan digunakan. Dengan adanya materi yang diberikan oleh bidan dan dengan media yang mendukung jadi yang bermula pasien tidak mempunyai pengetahuan sama sekali tentang $\mathrm{KB}$ sebelum konseling menjadi yakin dengan KB yang akan dipilih.

Tabel Distribusi frekuensi cakupan KB di RSIA Prima Husada Waru 2011

\begin{tabular}{l|c|c}
\hline Jenis KB & Jumlah & Prosentase(\%) \\
\hline PIL & 10 & 20 \\
\hline Suntik & 10 & 20 \\
\hline Implan & 10 & 20 \\
\hline AKDR & 10 & 20 \\
\hline MOW/MOP & 10 & 20 \\
\hline \multicolumn{1}{c}{ Jumlah } & 50 & 100 \\
\hline
\end{tabular}


Sumber : Data primer, 2011

Dari tabel diatas dapat dilihat bahwa jumlah Cakupan KB setara dengan jenis kontrasepsi lainnya karena disini populasi yang diambil setiap KB sama besarnya.

Dapat dilihat dari teori bahwa ada beberapa factor yang mempengaruhi cakupan AKDR. Namun pada kenyataannya AKDR kurang diminati oleh para akseptor dikarenakan takut cara pemasangan yang rumit dan juga harga yang terlalu mahal jika dilihat dari kelebihan AKDR banyak kelebihan yang memudahkan para akseptor untuk menggunakan AKDR. AKDR merupakan progam pemerintah untuk menekankan jumlah AKI dan AKB dan juga untuk menekankan jumlah penduduk. Factor lain yang mempengaruhi akseptor tidak menggunakan AKDR yaitu dilarang oleh agama. Hukum dari tiap-tiap agama untuk menggunakan alat kontrasepsi khususnya AKDR kemungkinan berbeda. Sebagai contoh masyarakat pedesaan yang beragam Islam merasa takut akan dosa sekiranya memakai AKDR paling tidak alat kontrasepsi yang dipakai atas petunjuk dan persetujuan dari tokoh agama ataupun suami. Ada juga kepercayaan yang mengatakan bahwa suntik merupakan obat yang sangat mujarap sehingga masyarakat lebih banyak menggunakan suntik dari pada AKDR

Tabel Tabulasi silang Hubungan antara pelayanan konseling dengan Cakupan AKDR di RSIA Prima Husada Waru - Sidoarjo bulan September 2011

\begin{tabular}{|c|c|c|c|c|c|c|c|c|c|c|c|}
\hline \multirow[b]{2}{*}{$\begin{array}{l}\text { Pelayanan } \\
\text { konseling }\end{array}$} & \multicolumn{2}{|c|}{ AKDR } & \multicolumn{2}{|c|}{ Pil } & \multicolumn{2}{|c|}{ Suntik } & \multicolumn{2}{|c|}{ Implan } & $\begin{array}{l}\text { MOW / } \\
\text { MOP }\end{array}$ & \multicolumn{2}{|c|}{ Total } \\
\hline & & & & & & & & & & & \\
\hline Baik & 0 & 5 & 0 & 5 & 0 & 5 & 0 & 5 & & 20 & 100 \\
\hline Kurang Baik & & & & & & & & & & & \\
\hline
\end{tabular}




\begin{tabular}{l|l|l|l|l|l|l|l|l|l|l|l|l}
\hline & & & & & & & & & 0 & 00 & 0 & 00 \\
\hline
\end{tabular}

Sumber : Data Primer, 2011

Dari tabel diatas menunjukkan bahwa

bidan di RSIA Prima Husada Waru-

Sidoarjo sebagian besar melakukan

konseling dengan baik sebanyak 40 orang

dengan prosentase $80 \%$ sedangkan

sebagian kecil tidak melakukan konseling

sebanyak 10 orang dengan prosentase

$20 \%$.

\section{DAFTAR PUSTAKA}

1. Anggraini, Yetti. 2012. Pelayanan Keluarga Berencana. Jakarta:

Barata Niaga Media

2. Arikunto, S. 2002. Prosedur

Penelitian Suatu Pendekatan

Praktek. Jakarta : Rineka Cipta.

3. Angsar, Ilyas. 2003. Progam Pelayanan Keluarga Berencana. Jakarta: Barbara Kenji dkk

4. BKKBN. 2003. Teknik pengembangan konseling. Jawa Timur: BKKBN

5. BKKBN. 2003. Pelatihan Keterampilan komunikasi Interpersonal atau Konseling. Jakarta: BKKBN

6. BKKBN. 2004. Informasi Pelayanan Kontrasepsi Edisi Keempat. Jakarta: BKKBN
Hasil uji statistik menggunakan uji chisquare didapatkan hasil signifikan $p=$ 0.179 sehingga $\mathrm{p}>\bar{\alpha}$, hal ini menunjukkan bahwa tidak ada hubungan antara pelayanan konseling dengan cakupan AKDR. Diharapkan walaupun tidak ada hubungan bidan ataupun tenaga kesehatan tidak menyepelehkan konseling terhadap akseptor baru.

7. Everett, Suzzanne. 2008. Buku Saku Kontrasepsi dan Kesehatan Seksual Reproduksi. Jakarta: EGC

8. Gebbie, Ailsa. 2006. Keluarga Berencana. Jakarta: EGC

9. Glasier, Anna. 2006. Keluarga Berencana dan Kesehatan Reproduksi. Jakarta: EGC

10. Handayani, Sri. 2010. Buku Ajar Pelayanan KB keluarga Berencana. Yogyakarta: Pustaka Rihana

11. Hartanto, Hanafi. 2003. Keluarga Berencana dan kontrasepsi. Jakatra: Pustaka Sinar Harapan

12. Ida Bagus gde, Manuaba, Prof. Dr. 1999. Ilmu kebidanan penyakit Kandungan dan Keluarga Berencana. Jakarta: EGC

13. Mamik.Dr. SKM. M.Mkes. 2011. Metode Penelitian kesehatan Dan penelitian. Sidoarjo: Print Media 
14. Martini. 2012. Pelayanan keluarga Berencana. Yogyakarta: Rohima Press

15. Mochtar, Rustam 1998. Sinopsis Obstetri. Obstetro Operatif. Operatif Sosial jilid 2 edisi 2. Jakarta: EGC

16. Prawiroharjo, Sarwono. 2008. Buku Panduan praktis Pelayanan
Kontrasepsi. Jakarta: Yayasan Bina Pustaka

17. Sasmita, Populasi jumlah penduduk.http:/otomotif.news.viva. co.id/news/read/291988-animober-kb-warga-jawa-timur (2 juli 2012) 